\title{
An intermediary as a trust enabler in a spatial business ecosystem
}

Jukka Majava, Tuomo Kinnunen, Del Foit, Pekka Kess, (2016) "An intermediary as a trust enabler in a spatial business ecosystem", International Journal of Innovation and Learning, Vol. 20, No. 2, pp. 199213. The final publication is available at: https://doi.org/10.1504/IJIL.2016.077845

\section{Jukka Majava*, Tuomo Kinnunen, Del Foit** and Pekka Kess}

Industrial Engineering and Management

University of Oulu

P.O. Box 4610

FI-90014, Finland

**Rady School of Management

University of California San Diego

9500 Gilman Dr., La Jolla, CA 92093

USA

E-mail: jukka.majava@oulu.fi

E-mail: tuomo.kinnunen@oulu.fi

E-mail: dfoit@ucsd.edu

E-mail: pekka.kess@oulu.fi

*Corresponding author

\begin{abstract}
Business ecosystems have changed the nature of competition among regions. Various organisations have been established to catalyse local innovation, such as CONNECT in San Diego, California, USA. This study explores the role of an intermediary organisation in establishing trust in a business ecosystem. This paper presents literature findings on business ecosystems, innovation in a spatial context, trust, and previous studies about San Diego. The empirical part of the study includes an analysis of the health and life sciences business ecosystem in San Diego, the role of trust, and how an intermediary organisation contributes to the ecosystem. The study demonstrates that trust is important for the ecosystem's success, and an intermediary organisation can increase the trust among the actors. The results indicate that decisionmakers should invest in accelerator and mentoring programmes to catalyse local innovation. Additionally, ecosystem members should participate in the intermediaries' activities to strengthen their ecosystem.
\end{abstract}

Keywords: business ecosystem; CONNECT; trust; innovation; life sciences; health sciences; intermediary organisation, learning.

Biographical notes: Jukka Majava (Dr Sc) works as a university lecturer in Industrial Engineering and Management at the University of Oulu, Finland. His industrial experience includes technology and ecosystem marketing, partner and project management, and business and supply chain development at Nokia Corporation. He has research interests in product innovation, business networks and supply chain development. 


\begin{abstract}
Author
Tuomo Kinnunen (MSc Tech) is a researcher in Industrial Engineering and Management at the University of Oulu. He has a master's degree in industrial engineering and management. Kinnunen has worked on several international research projects. His research work and interests include product development and business development, covering different angles.

Del Foit (MBA, BSc) is a lecturer at the University of California, Rady School of Management. He has over 30 years of experience in the life sciences industry, encompassing executive management responsibilities for operations, quality assurance, materials management, product development, information technology, distribution and customer support. During his professional career, Del held positions as chief operating officer at Sequenom, Inc., vice president of North American operations at Roche Diagnostics and director of operations at the Infectious Disease Business Unit, Ortho Clinical Diagnostics.

Pekka Kess (Dr Sc, Dr Eng) is a professor of industrial engineering and management at the University of Oulu. He has extensive managerial experience from both universities and industrial enterprises. He has worked in managerial positions in chemical, steel and electronics industries, as well as in the software business. He has been an active project evaluator in the European Commission, as well as a manager of international research and development projects. His research areas cover business ecosystems, strategic management, production organisations, knowledge management with specialisation in knowledge transfer, and e-learning.
\end{abstract}

\title{
1 Introduction
}

The nature of competition has changed; the competition has extended from a company level to business ecosystems (Moore, 1993). Additionally, many regions and organisations have searched for new growth sectors since global competition has become more intense in traditional industries. One potential source of economic growth is the health and life sciences sector due to rapid technological advancements and demographic changes in developed countries.

The life sciences focus on "the study of living organisms, including biology, botany, zoology, microbiology, physiology, biochemistry, and related subjects" (Oxford Dictionaries, 2015), whereas the health sciences can be considered a branch of the life sciences, including medicine and medical science areas and related sub-disciplines. Health organisations deal with prevention, diagnosis and treatment of diseases, as well as health-related education, research and outreach (Omachonu and Einspruch, 2010). In this paper, the health and life sciences sector is considered to include all public and private actors that are in the business of contributing to human health. This sector comprises various product and service companies, universities, research institutions, intermediaries and public actors.

The USA is the global leader in the life sciences sector, for example, in terms of the number of patent applications. The Greater Boston area, the San Francisco Bay area and San Diego are the top three regions in the life sciences in the USA (Jones Lang LaSalle [JLL], 2014). Past research has mostly focused on the Greater Boston and San Francisco Bay areas. However, San Diego has also received academic interest in recent years.

Previous studies (e.g. Casper, 2007; Kim, 2013; Walcott, 2002; Walshok and Shragge, 2014) have provided valuable insights into San Diego's innovation economy, including the roles of University of California San Diego (UCSD) and pioneer companies, the importance of social networks, cultural aspects and collaborative learning in the region. The present study aims to 
Title

analyse San Diego's health and life sciences sector by utilising the business ecosystem concept in a spatial context.

Trust is important for organisations and can improve enterprises' innovativeness (Harorimana, 2013; Sankowska, 2013). Trust can also be considered a vital element of successful business ecosystems (Chesbrough et al., 2014). The significance of trust has been emphasised, for example, by Kandiah and Gossain (1998), who claim that customers prefer a single trusted source in new business ecosystems. Inter-firm trust development in business ecosystems has also gained academic interest (e.g. Liu, 2015). Our research applies the model proposed by Mayer et al. (1995, p. 712), who define trust as "the willingness of a party to be vulnerable to the actions of another party based on the expectation that the other will perform a particular action important to the trustor, irrespective of the ability to monitor or control that other party". Our study focuses on the role of the intermediary organisation called CONNECT in the ecosystem, whose establishment has been identified as a key event in San Diego's development (Porter, 2001). The research questions are as follows:

1. What is the role of trust in San Diego's health and life sciences business ecosystem?

2. How does CONNECT affect trust in the ecosystem?

This paper includes a literature review and an empirical study. The literature topics include business ecosystems, innovation in a spatial context, and previous studies about San Diego. Mayer et al.'s (1995) model of trust is also described. The empirical study is based on the case study method.

\section{Literature review}

\subsection{Business ecosystems}

Business ecosystems tie different actors together through knowledge flows and shared valuecreation processes (Iansiti and Levien, 2004; Moore, 1993). Business ecosystems develop through self-organisation, emergence and co-evolution (Peltoniemi and Vuori, 2004). Their life cycle typically includes four stages: birth, expansion, leadership, and self-renewal or death (Moore, 1993).

Ecosystems' rules result from the co-evolution and interactions among the participants. The keystone company and the level of control it assumes constitute a significant factor that affects the ecosystem internally. In turn, external factors influencing the ecosystem include changes in the social, economic, technological and competitive environments (Makinen and Dedehayir, 2012). Furthermore, the constraints are set by the competitive forces, regulators and legislation, standard-setting bodies, social norms and business ethics (Teece, 2007). Other actors adjust to the rules set by the lead actors (keystones or platform leaders) that may change in the future. However, the community (e.g. niche players and intermediaries) values the ecosystem leaders that enable the members to move towards a shared future and mutual benefits (Iansiti and Levien, 2004; Moore, 1993; 1996).

In business ecosystems, companies develop mutually beneficial relationships with customers, suppliers and competitors. The co-evolution occurs around a new innovation; organisations cooperate and compete to support new products, to satisfy customer needs and finally, to create succeeding innovations (Iansiti and Levien, 2004). Innovation and co-evolution are the main factors for change dynamism in business ecosystems (Majava et al., 2013). 


\section{Author}

\subsection{Spatial innovation}

Innovations require proper environmental conditions to exist (Trott, 2012). According to Casper (2013), the innovativeness and success of certain geographical regions can be viewed from three different perspectives: having universities as anchors of regional clusters, social networks as an enabling factor, and institutional frameworks. From a spatial viewpoint, the necessary environmental conditions include, for example, adequate basic research, angel investors willing to invest, talented people and capital (Suh, 2010). In turn, Hwang and Horowitt (2012) emphasise talent diversity, trust across social barriers, motivations above short-term rationality, and social norms that promote rapid collaboration and experimentation. In their view, talent, ideas and capital are the nutrients that move through the ecosystem.

The triple-helix type of collaboration among the academia, industry and government is claimed to accelerate innovations and the creation of new organisations and institutions, such as venture capitalists (VCs) and incubators (Etkowitz and Leydesdorff, 1997; Mok, 2012). Therefore, many regions are trying to achieve an innovation environment that includes university spin-offs, initiatives for knowledge-based economic development, and boundary spanning and partnerships among companies, government laboratories and academic research groups. The innovation support initiatives also encompass financial assistance and the establishment of new foundations, organisational forms and programmes (Etkowitz and Leydesdorff, 2000).

\subsection{San Diego}

San Diego started to focus on research and development (R\&D) in the 1960s. The growth was supported by federal government investments and several research institutes, and the region was able to attract international companies and private investors in the 1980s. The role of three pioneer startup firms, Linkabit (wireless technology), ISSCO (computer graphics) and Hybritech (biotechnology), was also very important in creating growth in San Diego (Jones, 2005; Kim, 2013; Walshok and Shragge, 2014). In the early 1980s, the military sector started to decline, and traditional business development strategies were no longer working. The local economy needed to be extended beyond the traditional real estate, defence and tourism sectors. The leaders in San Diego understood that the gap between science and business had to be bridged. Excellent basic research existed, but interest in applications, technology transfer and commercialisation was limited. The business community had experience only in traditional industries, and venture capital funds, equity bankers and major financial institutions were not resident. Technology business networks in San Diego focused on government relations and procurement; professional and business services to support science-based innovation enterprises were missing (Walshok and Shragge, 2014). To tackle various challenges related to the growth and development of new startups (Muhos et al., in press), a formal support mechanism was needed. The University of California San Diego (UCSD) Program in Technology and Entrepreneurship, later UCSD CONNECT, was established. The programme targeted the development of contacts, social networks and business services that had not been available earlier. CONNECT's early key components included Meet the Entrepreneur and Meet the Researcher events, financial forums, Springboards for Technology Startups, The Most Innovative New Products Award, and various workshops that aimed to help scientists and businesspeople share practices and insights to create beneficial relationships (Walshok and Shragge, 2014).

Today, San Diego is one of the leading regions in the world in the life sciences and wireless technology sectors (JLL, 2014; Walshok and West, 2014). Various factors have contributed to San Diego's success. Walcott (2002) observes that the key success factors include a world-class research university, risk financing, an entrepreneurial culture, advocacy leadership and 
Title

appropriate real estate, together with an intensive information-exchange network. Social networks, interactions, and the importance of Hybritech and the startups established by its former employees have also been emphasised (Casper, 2007; Jones, 2005).

In the most recent studies, Hwang and Horowitt (2012) claim that San Diego's growth was catalysed by enterprise-friendly policies and transparent laws for real estate, intellectual property, agreements and corporations. Networks of people with experience in science, technology, business and business-related services, and the ability to attract global talent can also be considered important. Walshok and Shragge (2014) argue that the characteristics of the local culture include risk orientation, entrepreneurial talent, various "gateways" to develop ideas and opportunities, integrative civic platforms and the tendency to reinvest in the ecosystem. Kim (2013) perceives that creating and circulating local knowledge and practices, that is, collaborative learning, has been the main reason for San Diego's success. The universities' role in developing talent for local companies is also vital (Walshok and West, 2014).

\subsection{Trust}

Trust has been widely discussed in the academic literature and is considered a fundamental element in all social interactions, both actual and virtual (Chan and Ma, 2015; Gambetta, 2000). Working together typically involves interdependence, and people have to rely on others to achieve their objectives (Mayer et al., 1995). Trust is most often viewed as something that occurs between individuals, but some authors consider that organisational trust also exists; in other words, trust exists in impersonal and personal forms (Atkinson and Butcher, 2003). For example, Sankowska (2013) claims that inter-organisational trust fosters company innovativeness due to the knowledge creation and transfer between collaborating parties. One of the most well-known studies of trust has been conducted by Mayer et al. (1995), whose model of trust is presented in Figure 1.

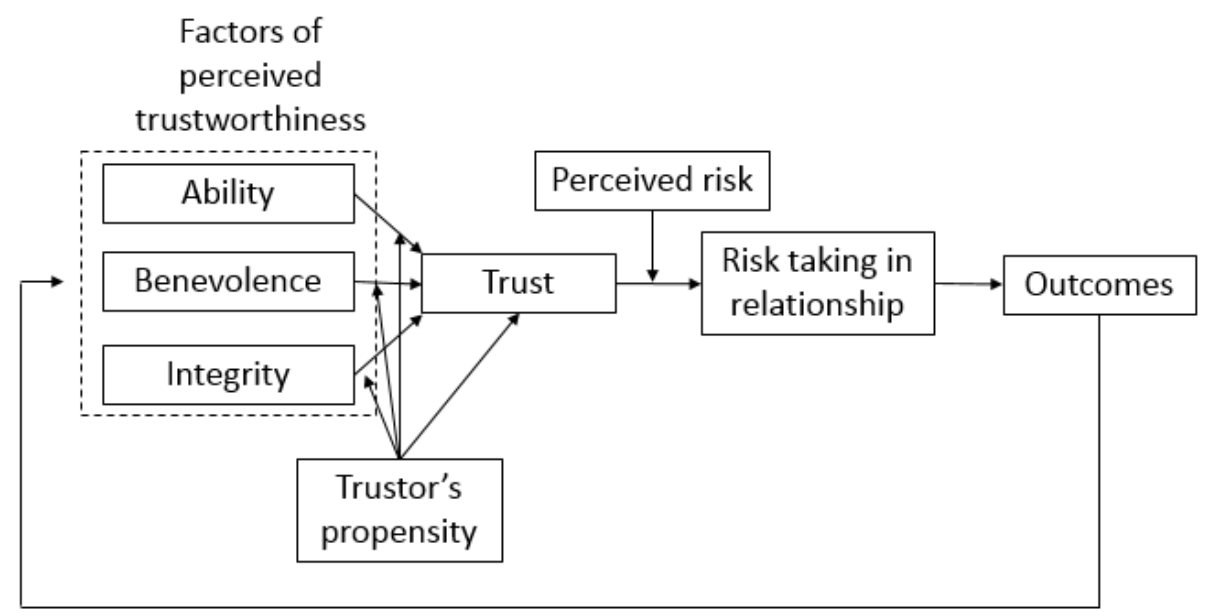

Figure 1. Model of trust (Mayer et al., 1995)

Figure 1 illustrates that the factors of perceived trustworthiness include a trustee's ability, benevolence and integrity. Ability means the "group of skills, competencies, and characteristics 
Author

that enable a party to have influence within some specific domain". In turn, benevolence is "the extent to which a trustee is believed to want to do good to the trustor, aside from an egocentric profit motive". Integrity involves "the trustor's perception that the trustee adheres to a set of principles that the trustor finds acceptable". In addition to the factors of perceived trustworthiness, trust is also affected by a trustor's propensity for it, a "general willingness to trust others" (Mayer et al., 1995 pp. 715, 717-719).

Risk taking in a relationship is the outcome of trust; it is a function of trust and perceived risk, which involves the trustor's belief in the possibilities for "gains or losses outside of considerations that involve the relationship with the particular trustee". Finally, the level of trust evolves over time as the parties interact. This is illustrated by the feedback loop, from the outcomes of risk taking in a relationship to the factors of a trustee's perceived trustworthiness. When risk taking leads to a positive outcome, the trustor's views of the trustee improve. Similarly, negative outcomes lead to declining perceptions. The trust model proposed by Mayer et al. (1995) has been applied later in different contexts, for example, by Burke et al. (2009).

\section{Research method}

This research is based on the case study method. The research started with a literature review on business ecosystems, spatial innovation and trust, as well as previous studies about San Diego. The data collection for the empirical study involved interviewing twenty informants with in-depth knowledge of San Diego's health and life sciences ecosystem; they consisted of academic leaders, business executives, advisors, entrepreneurs and investors. Five interviewees represented a university, and another five came from different companies. Three informants were from trade organisations, three belonged to the incubator and accelerator types of organisations, two represented research institutes, and two were investors. Many of the interviewees also had multiple roles and were involved in more than one organisation.

Semi-structured interviews were utilised. The interviews lasted approximately one hour each on average, and they were recorded and transcribed for analysis. The interviews started with generic questions about the informants' backgrounds and views of business ecosystems. Next, the questions specifically addressed San Diego's health and life sciences sector, the ecosystem's main actors, the CONNECT organisation and the role of trust in the ecosystem.

The data was analysed by using a qualitative approach (Eisenhardt, 1989); the interview transcripts were read several times, each time delving deeper into the data to find connections, patterns and juxtapositions. The identified patterns were structured into more generic categories to formulate the key concepts and issues.

\section{Findings}

\subsection{Actors and their roles in the ecosystem}

The health and life sciences business ecosystem in San Diego includes hundreds of companies and other organisations. Universities and research institutes, such as the UCSD and the Salk 
Title

Institute, are important in the ecosystem due to their capabilities to obtain research funding, create new technologies and ideas for commercialisation, train new talent and license technologies.

In addition to ideas and talent, the ecosystem needs capital to function. Angel investors, most importantly the San Diego Tech Coast Angels, provide seed investments and advice for startups. Venture capitalists support innovation and company growth by making investments in the later stages. Prominent local VCs include Avalon Ventures, among others. However, the VCs are mainly located in the San Francisco Bay area, outside the spatial ecosystem.

Large pharmaceutical companies (e.g. Johnson \& Johnson) can be regarded as potential partners of and investors in new companies. Some of the pharmaceutical companies undertake R\&D activities in San Diego, whereas others use scouts to spot new innovations. Hundreds of other health and life sciences companies exist in the ecosystem. These companies operate in different fields, including biopharmaceuticals, biotechnology, diagnostics, genomics, medical devices and wireless healthcare. The more established companies contribute to the continuous success of the ecosystem and provide a talent pool for new companies. In turn, healthcare providers are the target market, a channel to end customers, and an important partner in clinical trials in the ecosystem. The most prominent healthcare providers in San Diego include Sharp Healthcare, Scripps Health, the UCSD Health System and Kaiser Permanente.

San Diego's health and life sciences business ecosystem involves dozens of intermediary organisations, comprising accelerators, incubators and trade organisations. Accelerator organisations and programmes, such as CONNECT Springboard and the UCSD von Liebig Center, provide structured mentoring, coaching and networking. The accelerators also match companies with early-stage funding opportunities. The incubators' role is somewhat different from that of the accelerators. The incubators offer space, resources and mentoring for startups. The most prominent incubators in San Diego have been identified as Janssen Labs and EvoNexus. Trade organisations, such as Biocom and the Wireless-Life Sciences Alliance, provide advocacy and resources for member companies that are typically more established than startups. The trade organisations also offer local and global networking opportunities.

The role of governments has also been found to be important in the ecosystem. The local, state and federal governments provide the ecosystem with the infrastructure, rules (legislation, regulations and taxes), policies and research funding. Finally, the ecosystem includes business service providers, offering legal, financial, real estate and human resource services. In addition to their core services, the providers support the functioning of the ecosystem via their contact networks.

\subsection{Trust in the ecosystem}

The interview analysis shows that trust plays a crucial role in San Diego's health and life sciences business ecosystem. Trust is characterised as a precondition for the existence of a capitalistic society and any business ecosystem. It is also perceived as the basic foundation of business relationships. Without trust, investors do not invest. Trust is considered "the most expensive part of any transaction", which often needs to be reinforced with legal agreements to protect intellectual property. Trust is viewed as being about credibility, in other words, fulfilling promises and protecting confidential information. 


\section{Author}

The types of trust are considered to include pre-transactional trust, which is created by being acquainted with each other and may or may not be activated in a future transaction. Working together towards a common goal is regarded as creating opportunistic trust. Virtual trust, in turn, is deemed to be earned through recommendations and introductions by a trusted person. More extensive aspects of trust have also been brought up. People must be able to trust the whole system. In other words, laws must be clear and implemented consistently; otherwise, investments are not made. From the ecosystem perspective, trust means that all actors must understand what they do best, perform it well and have confidence that others will do their part. However, it has also been noted that this may be difficult since organisations often work in silos and compete for the same capital.

Most informants report that trust between people is gained through getting to know each other. It is stressed that intermediaries, such as CONNECT and Biocom, are important because they provide events and venues for people to meet, build knowledge about one another and sustain existing relationships. Some informants also point out that people tend to trust people they like.

From an institutional point of view, scientific integrity and reputation are considered helpful in building trust. On the other hand, a UCSD representative observes that it is not easy to make small companies trust a large university; therefore, it is essential to be as clear and transparent as possible about university processes.

Overall, many informants note that trust and reputation are very important in San Diego; people who cannot be trusted become known very quickly in a relatively small community. Due to constant changes in the ecosystem, people cannot rely on working in the same company for decades; a solid reputation gives a person the next job opportunity. The "parking lot principle" has also been brought up, as in many cases, it is possible for people to move on to another company without changing the parking lot that they use, provided that they have a good reputation.

Many informants emphasise that San Diego has a culture of collaboration, openness in sharing ideas, and helping others. It is observed that a community of similar interests exist, and many people are dedicated to contributing to San Diego's success. One informant points out, "Trust is the promise we 're trying to accomplish". This involves people supporting one another, companies maintaining their high performance, VCs continuing to invest, pharmaceutical companies continuing to license and so forth. Some examples of helping others include providing office space or services for free to people starting their own businesses, according to the "pay it forward" principle.

Because many people have come to San Diego from elsewhere, trust is not regarded as being based on a common background. Pioneer companies, including Hybritech and Linkabit in the 1980s, are mentioned as "roots of family trees" in the ecosystem. Helping others is not considered to provide direct immediate benefits, but many interviewees acknowledge that the ecosystem's success helps everyone over the long term. Even competitors might be helped if the information provided to them is non-confidential. However, it is also pointed out that the local collaboration may not differ from that of other locations although it is promoted more in San Diego. 
Title

\subsection{CONNECT}

CONNECT is claimed to be one of the reasons behind San Diego's success in creating new innovations. CONNECT is a non-profit organisation established at the UCSD in 1985. Its first leader, Bill Otterson, was characterised as a very vigorous person, to whom "you could not say no". Traditional business strategies and practices did not support building trust in San Diego region. Collaboration among companies in vertical industries was deemed inappropriate as companies focused on their unique competitiveness. The implementation of CONNECT's strategies and business practices can been considered vital for building trust among actors in San Diego's ecosystem. CONNECT's principles, which can be seen to be derived from the Otterson culture, included help each other - compete in the marketplace, the team above self, the region above company, political issues matter (e.g. Food and Drug Administration (FDA) reform) and it is acceptable to fail as long as you try again. The first fifteen years of the organisation were very successful, but they were followed by a decline after Otterson's death in 1999. In 2006, its new leader, Duane Roth, turned CONNECT into a more influential organisation again; it was spun off from the UCSD to become an independent organisation and started its lobbying activities in Washington DC. The UCSD still operates a separate entity called Global CONNECT, responsible for international activities. When Roth died in 2013, Greg McKee was nominated to lead CONNECT.

The interview analysis proves that CONNECT is a vital element of San Diego's health and life sciences business ecosystem. The organisation can be viewed as an accelerator and a catalyst of innovations, connecting scientists, entrepreneurs and investors. Furthermore, it has evolved to become a lobbyist and promoter of San Diego businesses, both locally and nationally. CONNECT also manages several education programmes. One informant describes CONNECT as "the go-to organisation in town". The organisation has greatly influenced the business culture in San Diego. In events arranged by CONNECT, a lot of time is reserved for networking, which enables people to create new connections and maintain the strength of existing relationships.

Most informants regard the Springboard mentoring programme for startups as the "heart and soul" of CONNECT. Springboard provides a learning process that involves many phases, covering application and pre-screening, as well as the intake, marketing, finance, dry-run and final panels. In total, 397 companies were assisted by the Springboard programme in 2005-2014. Since 1993, companies assisted by CONNECT have raised approximately $\$ 1.4$ billion in capital (CONNECT, 2014).

CONNECT offers many other valuable programmes, including Entrepreneurs-in-residence, Most Innovative Product and the MIT Enterprise Forum. Some informants also deem different education programmes important. The value that the volunteer mentors provide for a new startup is considered very important and worth "tens of thousands of dollars of consulting time". Many activities are extremely dependent on the availability of mentors, and some interviewees admit that finding time for mentoring is often a challenge for them.

While many CONNECT activities are found to be important, some informants argue that the value of other programmes, such as Connect with CONNECT, is questionable. These "more social events" make the organisation appear less serious, business-wise. The organisation is also characterised as "a victim of its own success". Over the years, CONNECT has noted many gaps in the ecosystem, and other organisations, such as Biocom, have started to fill in the gaps. Some 


\section{Author}

informants report that it is sometimes difficult to recognise the core mission of CONNECT, and some of its roles overlap with Biocom's functions.

Many informants predict that the future of CONNECT will involve constant evolution and refinement. While the organisation is identified as a critical element of the ecosystem, some interviewees point out that it should return to its roots, focus on its original core mission and potentially become part of the UCSD again. However, the transfer back to the UCSD will most likely not happen because public universities are not allowed to lobby on behalf of companies. Some informants also suggest that more efforts should be put into lobbying at the state and federal levels and increasing funding opportunities for companies. Finally, one informant states that the entry requirements of CONNECT Springboard may be too strict, which makes the programme risk averse and decreases radical innovation.

\subsection{Inter-personal trust in the ecosystem}

The study results were analysed by utilising the trust model proposed by Mayer et al. (1995). Table 1 describes how the health and life sciences ecosystem and CONNECT affect different elements of inter-personal trust in San Diego.

Table 1. Effects of ecosystem and CONNECT on inter-personal trust.

\begin{tabular}{|c|c|c|}
\hline Trust element & Ecosystem & CONNECT organisation \\
\hline $\begin{array}{l}\text { Trustee's } \\
\text { perceived } \\
\text { ability }\end{array}$ & $\begin{array}{l}\text { Attracts talented people with domain- } \\
\text { specific skills and competencies }\end{array}$ & $\begin{array}{l}\text { Provides a platform and tested methods } \\
\text { (e.g. Springboard) for the experts in } \\
\text { different domains to meet }\end{array}$ \\
\hline $\begin{array}{l}\text { Trustee's } \\
\text { perceived } \\
\text { benevolence }\end{array}$ & $\begin{array}{l}\text { Provides a shared vision - "The } \\
\text { ecosystem's success benefits everyone". }\end{array}$ & $\begin{array}{l}\text { Gives an initial attachment between the } \\
\text { trustor and the trustee and enables } \\
\text { gathering information on the trustee }\end{array}$ \\
\hline \multirow{2}{*}{$\begin{array}{l}\text { Trustee's } \\
\text { perceived } \\
\text { integrity }\end{array}$} & \multirow[t]{2}{*}{ Sets common rules and values } & Gathers people with similar interests \\
\hline & & $\begin{array}{l}\text { Provides some written and non-written } \\
\text { rules and practices for collaboration }\end{array}$ \\
\hline $\begin{array}{l}\text { Trustor's } \\
\text { propensity to } \\
\text { trust }\end{array}$ & - & - \\
\hline Perceived risk & Past successes increase belief in gains & $\begin{array}{l}\text { Promotes success stories and makes failure } \\
\text { more acceptable }\end{array}$ \\
\hline $\begin{array}{l}\text { Risk taking in } \\
\text { relationship }\end{array}$ & - & $\begin{array}{l}\text { Different events increase chances to engage } \\
\text { in trusting actions }\end{array}$ \\
\hline Outcomes & - & - \\
\hline
\end{tabular}

The second column in Table 1 shows that the ecosystem has many positive effects on different trust elements. First, the ecosystem attracts talented people with domain-specific skills and competencies. Second, the ecosystem gives people a shared vision, where they start to believe that the ecosystem's success benefits them also. Third, common rules and values in the ecosystem positively affect the trustor's views of the trustee's integrity. Fourth, past successes in the 
Title

ecosystem influence the level of perceived risk by increasing the trustor's views of possible gains. While it could be argued that the ecosystem attracts risk takers, the interview data does not indicate that the ecosystem has any effect on the trustor's propensity to trust, risk taking in a relationship, and outcomes. Generally, positive outcomes of risk taking in a relationship improve the perceptions about the trustee, whereas negative outcomes have an opposite effect.

The third column in Table 1 illustrates that CONNECT positively contributes to different trust elements. CONNECT provides a platform for the experts in different domains to meet and interact. It also provides an initial attachment between the trustor and the trustee and enables gathering information on the trustee in a safe environment. Different events organised by CONNECT attract people with similar interests, which increase the trustor's views of the trustee's integrity. The organisation also has some written and non-written rules and practices for collaboration. CONNECT promotes success stories, and information on failed startups makes failure more acceptable, which enhances the trustor's views of possible gains and reduces perceptions of possible losses. Numerous events organised by CONNECT increase the opportunities for people to engage in trusting actions. However, the data analysis does not indicate that CONNECT affects the trustor's propensity to trust, risk taking in a relationship, and outcomes. Nonetheless, it could be argued that CONNECT's activities result in more interactions and thus increase risk taking in relationships. A large amount of interactions increases the number of successes, which enhances the trust in the ecosystem.

\section{Discussion}

This study has focused on the health and life sciences business ecosystem in San Diego. Past research has stressed the importance of collaboration, collaborative learning and social networks in San Diego's ecosystem (e.g. Casper, 2007; Kim, 2013). Previous studies have also emphasised the roles of the UCSD, research institutes and pioneer companies (e.g. Jones, 2005; Walshok and West, 2014). Ecosystem thinking assumes that organisations develop mutually beneficial relationships and that the ecosystem members have a shared future and destiny (Iansiti and Levien, 2004). Our study supports the aforementioned assumptions and highlights the roles of trust and an intermediary organisation in the local ecosystem.

Trust has been found to be a fundamental element in all social interactions, and it can also improve enterprise innovativeness (Gambetta, 2000; Sankowska, 2013). The importance of trust for spatial innovation has been emphasised by Hwang and Horowitt (2012). In our study, trust is identified as the basic foundation of business relationships in the ecosystem. We have identified different types of trust, including virtual trust (i.e. recommendations by a trusted person). Our study also demonstrates more extensive aspects of trust from the ecosystem perspective; individual actors must be able to trust the entire system, such as laws and their implementation. The actors must understand their roles and believe that others do their part in the ecosystem. Organisations and individuals should consider the aforementioned factors to enhance the functioning of their ecosystems.

Our study suggests that becoming familiar with one another is a prerequisite for improving inter-personal trust. Thus, intermediary organisations, such as CONNECT, play a vital role in ecosystems. These organisations provide a platform for creating new and maintaining existing 
relationships. Our study supports previous findings (e.g. Walshok and Shragge, 2014) by indicating CONNECT as crucial for the San Diego region. Our study further elaborates on the multiple roles of CONNECT as an accelerator; catalyst; connector of scientists, entrepreneurs and investors; lobbyist; promoter; and educator. The results suggest that CONNECT has been able to transform the business culture in San Diego. One reason for this may be the considerable time allowed for networking in CONNECT's events. The time reserved enables individual actors to create new connections and maintain the strength of existing relations.

Kim (2013) discusses the importance of collaborative learning for San Diego's success. Our study finds that the Springboard mentoring programme for startups is the core activity of CONNECT. The Springboard can be considered a learning process that involves many phases, and the programme facilitates the collaborative learning that takes place in the region. Other valuable programmes of CONNECT include Entrepreneurs-in-residence, for instance. Overall, the value that the volunteer mentors provide for a new startup is regarded as vital. Therefore, decision-makers should consider investing in accelerator and mentoring programmes to catalyse local innovation and new business creation.

Our study indicates that CONNECT has various effects on different elements of trust (Mayer et al., 1995). Based on the results, the intermediary organisation can influence a trustee's perceived ability, benevolence and integrity. Moreover, the intermediary may reduce perceived risks and result in more chances to engage in trusting actions. Thus, our study indicates that an intermediary organisation can positively affect the trust among ecosystem actors. While regional innovation depends on various factors (e.g. Suh, 2010), and the best measures are often context dependent, decision-makers should consider utilising intermediaries to enhance trust in the local ecosystem. Finally, organisations and individuals should participate in the intermediaries' activities to strengthen their ecosystems.

\section{Conclusions}

The nature of competition has changed. Many regions and organisations seek new growth sectors due to intense global competition in traditional industries. The health and life sciences sector is a potential source of new growth. This paper has explored the roles of trust and CONNECT organisation in establishing a successful health and life sciences business ecosystem in San Diego.

Past research has highlighted the importance of collaboration, collaborative learning and social networks in San Diego's ecosystem. Previous studies have also stressed the roles of the university, research institutes and pioneer companies. The results of our study indicate that trust and intermediary organisations, especially CONNECT, are essential in the spatial business ecosystem. This study also provides new insights into different elements of inter-personal trust in the ecosystem. Our results reveal that an intermediary organisation can positively affect the trust among ecosystem actors. Based on the results, decision-makers should consider investing in accelerator and mentoring programmes to catalyse local innovation. Furthermore, organisations and individuals should find ways to participate in the intermediaries' activities to strengthen the local ecosystem. 
Title

This paper's limitations include the typical drawbacks of a single case study, which make the generalisation of the findings difficult. The recommended future research includes conducting similar studies in other spatial contexts to compare and validate the findings.

\section{Acknowledgements}

The authors thank the interviewees for their valuable inputs. The authors are grateful to the Finnish Funding Agency for Innovation (TEKES) and the UCSD Rady School of Management for supporting the Business Ecosystems and Platforms for Innovations (BECSI) project.

\section{References}

Atkinson, S. and Butcher, D. (2003) 'Trust in managerial relationships', Journal of Managerial Psychology, Vol. 18, No. 4, pp. 282-304.

Burke, C. S., Sims, D. E., Lazzara, E. H., and Salas, E. (2007) 'Trust in leadership: A multi-level review and integration', The Leadership Quarterly, Vol. 18, No. 6, pp. 606-632.

Casper, S. (2007) 'How do technology clusters emerge and become sustainable?: Social network formation and inter-firm mobility within the San Diego biotechnology cluster', Research Policy, Vol 36, No 4, pp. 438-455.

Casper, S. (2013) 'New-technology clusters and public policy: Three perspectives', Social Science Information, Vol. 52, No. 4, pp. 628-652.

Casper, S. (2014) 'The University of California and the evolution of the biotechnology industry in San Diego and the San Francisco Bay area', in Kenney, M. and Mowery, D. (Eds.), Public Universities and Regional Growth: Insights from the University of California, Stanford University Press, pp. 66-96.

Chan, W. W. and Ma, W. W. (2015) 'An empirical investigation on key determinants of social media trust', International Journal of Innovation and Learning, Vol. 18, No. 2, pp. 151-167.

Chesbrough, H., Sohyeong, K., and Agogino, A. (2014) 'Chez panisse: Building an open innovation ecosystem', California management review, Vol. 56, No. 4, pp. 144-171.

CONNECT. (2014) Springboard \& Capital Competition impact assessment report [online] Report, CONNECT organisation, San Diego, USA. http://connect.org/programs/Impact-Report/SB-ImpactAssessment-Report-2005-1H2014-digital.pdf (Accessed 23 August 2015).

Eisenhardt, K.M. (1989) 'Building theories from case study research', Academy of Management Review, Vol. 14, No. 4, pp. 532-550.

Etzkowitz, H. and Leydesdorff, L. (1997) Universities and the Global Knowledge Economy: A Triple Helix of University-Industry-Government Relations, Cassell Academic, London.

Etzkowitz, H. and Leydesdorff, L. (2000) 'The dynamics of innovation: From national systems and "mode 2" to a Triple Helix of university-industry-government relations', Research Policy, Vol. 29, No. 2, pp. $109-123$.

Gambetta, D. (2000) 'Can We Trust Trust?', in Gambetta, D. (Ed.), Trust: Making and Breaking Cooperative Relations, Department of Sociology, University of Oxford, pp. 213-237.

Harorimana, D. (2013) 'Innovation and learning through knowledge gatekeepers: A critical examination of the relationship between trust, openness, and the use of gatekeepers in organisations', International Journal of Innovation and Learning, Vol. 14, No. 3/4, pp. 350-382. 


\section{Author}

Hwang, V.W. and Horowitt, G. (2012) The Rainforest: The Secret to Building the Next Silicon Valley, Regenwald, Los Altos Hills, California, USA.

Iansiti, M. and Levien, R. (2004) 'Strategy as ecology', Harvard Business Review, Vol. 82, No. 3, pp. 68$78+126$.

JLL. (2014) Life Sciences Cluster Report [online] Report, Jones Lang LaSalle, Chicago, Illinois, USA. http://www.jll.com/services/industries/life-sciences/global-cluster-report (Accessed 2 June 2015).

Jones, M. P. (2005) Biotech's Perfect Climate: The Hybritech Story. PhD Thesis, University of California San Diego, USA.

Kandiah, G. and Gossain, S. (1998) 'Reinventing value: The new business ecosystem', Strategy \& Leadership, Vol. 26, No. 5, pp. 28-33.

Kim, S. T. (2013) 'Regional advantage of cluster development: A case study of the San Diego biotechnology cluster', European Planning Studies, Vol. 23, No. 2, pp. 238-261.

Liu, Z. (2015) 'Understanding inter-firm trust from business ecosystem perspective: Cases from the current Chinese animation industry', Journal of Business and Economics, Vol. 6, No. 5, pp. 879-890.

Majava, J., Isoherranen, V., and Kess, P. (2013) 'Business collaboration concepts and implications for companies', International Journal of Synergy and Research, Vol. 2, No. 1, pp. 23-40.

Makinen, S. J. and Dedehayir, O. (2012) 'Business ecosystem evolution and strategic considerations: A literature review', in Proceedings of Engineering, Technology and Innovation (ICE), 18th International ICE Conference, Munich, Germany, 18-20 June 2012, pp. 1-10.

Mayer, R. C., Davis, J. H. and Schoorman, F. D. (1995) 'An integrative model of organizational trust', Academy of management review, Vol. 20, No. 3, pp. 709-734.

Mok, K.H. (2012) 'The quest for innovation and entrepreneurship: the changing role of university in East Asia', Globalisation, Societies and Education, Vol. 10, No. 3, pp. 317-335.

Moore, J.F. (1993) 'Predators and prey: A new ecology of competition', Harvard Business Review, Vol. 71, No. 3, pp. $75-86$.

Moore, J.F. (1996) The Death of Competition: Leadership \& Strategy in the Age of Business Ecosystems, HarperBusiness, New York.

Muhos, M., Kess, P., Rasochova, L. and Foit, D. (in press) 'Early stages of technology-intensive companies in California', International Journal of Innovation and Learning.

Omachonu, V. K. and Einspruch, N. G. (2010) 'Innovation in healthcare delivery systems: A conceptual framework', Innovation Journal, Vol. 15, No. 1, pp. 2-20.

Oxford Dictionaries. [online]: http://www.oxforddictionaries.com/definition/english/lifesciences?q=life+sciences (Accessed 2 June 2015).

Peltoniemi, M. and Vuori, E. (2004) 'Business ecosystem as the new approach to complex adaptive business environments', in Proceedings of eBRF 2004, Tampere, Finland, 2004, pp. 267-281.

Porter, M.E. (2001) Clusters of innovation initiative: San Diego [online] Report, Council on Competitiveness, Washington, DC, USA. http://www.compete.org/publications/detail/218/clusters-ofinnovation-initiative-san-diego (Accessed 18 August 2015).

Suh, N.P. (2010) 'A theory of innovation and case study', International Journal of Innovation Management, Vol. 14, No. 5, pp. 893-913.

Sankowska, A. (2013) 'Further understanding of links between interorganisational trust and enterprise innovativeness - from a perspective of an enterprise', International Journal of Innovation and Learning, Vol. 13, No. 3, pp. 308-321. 
Title

Teece, D.J. (2007) 'Explicating dynamic capabilities: The nature and microfoundations of (sustainable) enterprise performance', Strategic Management Journal, Vol. 28, No. 13, pp. 1319-1350.

Trott, P. (2012) Innovation Management and New Product Development, Pearson Education Limited, Harlow, UK.

Walcott, S. M. (2002) 'Analyzing an innovative environment: San Diego as a bioscience beachhead', Economic Development Quarterly, Vol. 16, No. 2, 99-114.

Walshok, M. and Shragge, A. (2014) Invention and Reinvention: The Evolution of San Diego's Innovation Economy, Stanford University Press, Stanford, California.

Walshok, M and West, J. (2014) 'Serendipity and symbiosis: UCSD and the local wireless industry', in Kenney, M. and Mowery, D. (Eds.), Public Universities and Regional Growth: Insights from the University of California, Stanford University Press, pp. 127-152. 